Authors: Christeson, GL, Collins, GS, Morgan, JV, Gulick, SPS, Barton, PJ, Warner, MR, Title: Mantle deformation beneath the Chicxulub impact crater Journal: Earth and Planetary Science Letters, 2009, Vol: 284, Pages: 249 - 257 DOI: doi:10.1016/j.eps1.2009.04.033 


\section{Mantle deformation beneath the Chicxulub impact crater}

2 Gail L. Christeson ${ }^{1}$, Gareth S. Collins ${ }^{2}$, Joanna V. Morgan², Sean P.S. Gulick ${ }^{1}$, Penny J. Barton ${ }^{3}$,

3 Michael R. Warner².

$4{ }^{1}$ University of Texas Institute for Geophysics, Jackson School of Geosciences, J.J. Pickle

5 Research Campus, Mail Code R2200, 10100 Burnet Rd, Austin, Texas 78758, USA. ${ }^{2}$ Department

6 of Earth Science and Engineering, South Kensington Campus, Imperial College, London SW7

$72 \mathrm{AZ}, \mathrm{UK} .{ }^{3}$ Bullard Laboratories, Department of Earth Sciences, University of Cambridge,

$8 \quad$ Cambridge CB2 3EQ, UK.

ABSTRACT

The surface expression of impact craters is well-known from visual images of the Moon,

11 Venus, and other planets and planetary bodies, but constraints on deep structure of these

12 craters is largely limited to interpretations of gravity data. Although the gravity models are

13 non-unique, they do suggest that large impact craters are associated with structure at the

14 base of the crust. We use seismic data to map Moho (crust-mantle interface) topography

15 beneath the Chicxulub crater, the youngest and best preserved of the three largest known

16 terrestrial impact craters. The Moho is upwarped by $\sim 1.5-2 \mathrm{~km}$ near the center of the

17 Chicxulub crater, and depressed by $\sim 0.5-1.0 \mathrm{~km}$ at a distance of $\sim 30-55 \mathrm{~km}$ from the crater

18 center. A comparison with numerical modeling results reveal that immediately following

19 impact a transient crater reached a maximum depth of at least $30 \mathbf{~ k m}$ prior to collapse, and

20 that subsequent collapse of the transient crater uplifted target material from deep below

21 the crater floor. These results demonstrate that deformation from large terrestrial impacts

22 can extend to the base of the continental crust. A similar Moho topography is also modeled

23 for some large lunar and Martian craters, which suggests that mantle deformation may

24 play a prominent role in large crater formation. 
25 Keywords: Chicxulub, terrestrial impact, Moho, crater.

\section{INTRODUCTION}

The morphology of impact craters changes with size, progressing from small simple bowlshaped craters to large multi-ring craters (e.g., Gilbert, 1893; Dence, 1965; Hartmann, 1972; Schultz, 1976; Wilhelms et al., 1987; Melosh, 1989). The formation of small craters is fairly well understood from terrestrial field studies and laboratory tests, but the construction of large craters is not easily extrapolated from these observations since the kinematics of cratering change with size (e.g., Melosh, 1989). Thus it is essential to obtain constraints on the deep structure of impact craters in order to further our understanding of the formation of large impact craters.

Visual images from the Moon, Venus, and other planets and planetary bodies constrain the surface expression of different crater types, but provide no subsurface information. Gravity data over these craters offer some control on deeper crater structure; however, gravity models are non-unique with trade-offs between density contrasts, interface topographies, and layer thicknesses. Nonetheless, mantle upwarping beneath many large lunar and Martian craters is modeled from gravity data, and has been attributed to rapid mantle uplift following impact (e.g., Wise and Yates, 1970; Neumann et al., 1996; Wieczorek and Phillips, 1998; Neumann et al., 2004; Mohit and Philipps, 2007).

Mantle topography has also been inferred beneath the large terrestrial Chicxulub impact crater. Seismic reflection profiles image crater-related crustal reflectivity that extends to the base of the crust and in places may be associated with faulting at the crust-mantle boundary (Morgan et al., 1997; Morgan and Warner, 1999). Initial modeling of a two-dimensional wide-angle seismic refraction profile collected in 1996 suggested that the Moho may be upwarped at the crater center; however, resolution analyses indicate that a model with no mantle upwarping will also adequately fit these data (Christeson et al., 2001). The timescale of mantle upwarping is inferred to be rapid based on the absence of upwarping and/or thinning of post-impact sediments in the center of the basin. 
51 Here we analyze a more extensive dataset, using all seismic wide-angle data acquired in two

52 separate experiments to produce a well-constrained three-dimensional map of Moho topography

53 beneath the Chicxulub crater. These data show that the Moho is upwarped by $\sim 1.5-2 \mathrm{~km}$ near the

54 crater center, and depressed by $\sim 0.5-1.0 \mathrm{~km}$ at a distance of $\sim 30-55 \mathrm{~km}$ from the crater center.

55 We also compare these results with new numerical models of Chicxulub crater formation. These

56 results demonstrate that deformation from the Chicxulub impact extends to the base of the

57 continental crust.

58

59

60

61

62

63

64

65

66

67

68

69

70

71

72

73

74

\section{LOCATION AND SEISMIC EXPERIMENT}

The 180-200 km diameter Chicxulub structure, located in the northwest Yucatan ( Fig. 1), has been previously identified as the crater associated with the 65 Ma Cretaceous-Tertiary impact event (Hildebrand et al., 1991; Sharpton et al., 1992; Swisher et al., 1992). Other large terrestrial impact craters include the 2.02 Ga Vredefort crater in South Africa (250-300 km diameter) and the 1.85 Ga Sudbury crater in Canada (250-300 km diameter) (Grieve and Therriault, 2000). The Vredefort crater has been heavily eroded (Reimold and Gibson, 1996) and the Sudbury crater strongly deformed (Grieve and Therriault, 2000); in comparison the younger Chicxulub crater is relatively pristine owing to burial beneath $\sim 1 \mathrm{~km}$ of carbonate rocks (Morgan et al., 1997) and the tectonically quiescent location of the impact site.

The 1996 Chicxulub seismic experiment ( Fig. 1) consisted of $\sim 650 \mathrm{~km}$ of marine seismic reflection profiles recorded on 34 ocean bottom and 91 land seismometers (Morgan et al., 1997). The 2005 seismic experiment ( Fig. 1) acquired $\sim 1500 \mathrm{~km}$ of marine seismic reflection profiles

1 which were recorded on 28 ocean bottom and 87 land seismometers (Gulick et al., 2008).

2 Representative record sections that display crustal refractions $(P g)$ and Moho reflections $(P m P)$

3 are shown in Fig. 2. We utilized data from both field programs in our seismic analysis.

\section{3. METHODS}




\subsection{Crustal velocity structure.}

The goal of our seismic analysis is to map topography along the crust-mantle interface (Moho). However, inverting for the Moho interface requires that we first have a well-constrained three-dimensional crustal velocity structure that covers the entire region where instruments and shots are located that recorded $P m P$ reflections. We therefore utilized the tomographic method described by Zelt and Barton (1998) to constrain the three-dimensional structure of the region using the first-arrival picks to create a velocity grid. Similar inversions were presented in previous studies (Morgan et al., 2002; Vermeesch and Morgan, 2008; Vermeesch et al., 2009) but these were high-resolution models focused on the crater center; our analysis differs in that shots and receivers from the entire 1996 and 2005 seismic experiment are included and hence the velocity tomogram covers a larger volume (365 x 248 x $40 \mathrm{~km})$ but at a coarser resolution (1-km grid).

We picked all observed $P g$ first-arrival travel times for all seismometers at a 500-m spacing along each shot line. This resulted in a total of $\sim 125,000$ first-arrival picks. Our threedimensional starting velocity model was constructed by linearly interpolating between twodimensional velocity models previously obtained for profiles Chicx-A/A1 (Christeson et al., 2001), Chicx-B/F (Christeson et al., 2001), and Chicx-C (Brittan et al., 1999). The forward and inverse velocity grid were parameterized at $1.0 \mathrm{~km}$. The tomographic inversion was carried out for ten iterations, and at each iteration three smoothing parameters were tested. The final preferred model was chosen as the iteration that produced the smoothest model with a chi-square value of 1.0 (i.e., the model fits the observed travel-times within their estimated uncertainties which were set to 25 ms for source-receiver offsets $<30$ km, 50 ms for offsets 30-60 km, and 100 ms for offsets $>60 \mathrm{~km})$.

Four slices through the final velocity model are displayed in Fig. 3; plots show velocity anomaly with respect to average velocity for the entire region at each depth. Prominent features include a high-velocity anomaly near the crater center at $~ 5-10 \mathrm{~km}$ depth, a high-velocity region 
101 in the northwest, and a low-velocity region in the northeast. There is little ray coverage below

102 15-20 km depth, and thus these depths are not constrained by the tomographic inversion.

\section{3.2. Moho interface.}

104 We solved for Moho interface depth using the method presented by Zelt et al. (2003). This 105 technique uses one reflected phase $(P m P)$ to invert for one interface (the Moho) with a fixed 106 velocity model. We picked observed PmP secondary arrivals for all seismometers at a 500-m 107 spacing along each shot line, and set all pick uncertainties to $125 \mathrm{~ms}$. The crustal velocity model 108 obtained from tomographic inversion of first-arrivals was modified such that velocities were set 109 to $6.65 \mathrm{~km} / \mathrm{s}$ below $25 \mathrm{~km}$. This modification decouples the first-arrival and reflection 110 tomography inversions and results in an objective estimate of Moho depth (Zelt et al., 2003).

111 We inverted for both the most horizontal (flattest, Fig. 4a) and most smooth (smoothest, Fig. 112 4b) interface that fit the data with a chi-square value of 1.0. The resulting inversions are similar, 113 with shallow Moho near the crater center superimposed on a Moho dipping from west to east 114 approximately parallel to the coast. Our preferred model is the flattest Moho (Fig. 4a) because 115 there is less structure at the edges of our ray coverage. We removed a regional trend (Fig. 4c) 116 from the Moho interface and plot the resulting depth anomaly in Fig. 4d. The prominent 117 remaining feature in the Moho topography is an upwarping of 1.5-2.0 km near the crater center, 118 and a deepening of 0.5-1.0 km at a radial distance of $\sim 30-55 \mathrm{~km}$ from the center of the Moho 119 upwarping. The interface model is best-resolved within a radius of $75 \mathrm{~km}$ of the crater center 120 where $\sim 45,000$ reflections from the Moho interface are located.

121 Our inversion method for Moho interface depth assumes that all misfits between observed 122 and calculated $P m P$ travel times results from variability in interface depth. Alternatively, these 123 misfits might arise from variability in crustal velocities at depths not sampled by the first-arrival 124 tomographic inversion (>20 km). We therefore carried out a series of modeling tests to determine 125 the amplitude of crustal velocity anomalies required to reproduce the observed travel times near 126 the crater center. Our background velocity model is that used for the Moho interface inversion. 127 We calculated PmP travel times through this model that reflect off the regional Moho interface 
128 (Fig. 4c), and display the difference with the observed travel times in Fig. 5a. The radial distance

129 in this plot is the distance from the approximate center of the modeled Moho upwarping (Fig. 4)

130 at coordinates $(-89.51363,21.36184)$. The residuals are negative (observed earlier than

131 calculated) at a radial distance of $0 \mathrm{~km}$ where the interface model (Fig. 5b) contains Moho

132 upwarping. The best-fitting polynomial through the travel time residuals (red line in Fig. 5a)

133 changes from negative to slightly positive values at $\sim 25 \mathrm{~km}$. We can approximate these residuals

134 with fast crustal velocity anomalies at radial distances of $0-25 \mathrm{~km}$, and slow crustal velocity

135 anomalies at radial distances of 25-45 km. The modeling tests (Fig. 5c-e) indicate that deep

136 crustal velocity anomalies 5-15 km thick with amplitudes of 0.5-1.0 km/s near the crater center

137 can approximate the observed $P m P$ travel time misfits. We also estimated the gravity anomaly

138 produced by each of the models in Fig. 5, using the method of Talwani et al. (1959) and

139 assuming a standard relationship for velocity and density (Ludwig et al., 1970). The Moho

140 interface inversion model (Fig. 4a and Fig. 5b) will produce a +3 mgal gravity anomaly, while

141 the crustal velocity anomaly models (Figs. 5c-e) will produce anomalies of $\sim+15-25$ mgal; all

142 anomalies have a width of 90-100 km and are positioned near the crater center.

143 Previous studies (Vermeesch and Morgan, 2008; Vermeesch et al., 2009) conclude that the

144 observed gravity field (Fig. 1) can be adequately reproduced by well-constrained velocity

145 contrasts in the upper $20 \mathrm{~km}$ of the crust. For example, the central uplift in the upper crust is

146 associated with a velocity increase of $0.4-0.5 \mathrm{~km} / \mathrm{s}$ and correlates well with the position of the

147 gravity high located 10-20 km southwest of the crater center. Horizontal velocity variations

148 typically decrease with depth, and thus it is unlikely that velocity anomalies greater than the 0.4-

$1490.5 \mathrm{~km} / \mathrm{s}$ values observed for the central uplift are present in the deep crust. In addition the

150 calculated $15-25$ mgal positive gravity anomaly associated with these $0.5-1.0 \mathrm{~km} / \mathrm{s}$ anomalies is

151 not observed. Thus we argue that depth changes at the Moho interface are the most realistic

152 source for observed variations in $P m P$ travel times. 
153

154

155

156

157

158

159

160

161

162

163

164

165

166

167

168

169

170

171

172

173

174

175

176

177

178

179

\subsection{Numerical modeling.}

Formation of the Chicxulub impact crater has been the subject of many recent twodimensional numerical modeling studies (e.g., O'Keefe and Ahrens, 1999; Collins et al., 2002; Ivanov and Artemieva, 2002; Ivanov, 2005; Stewart and Senft, 2007; Collins et al., 2008), but none of these studies focused on the agreement between models and observation of Moho deformation. Therefore we performed new numerical modeling calculations to examine the Moho displacement predicted by vertical impact models for a range of impactor sizes.

To simulate the Chicxulub impact we used the iSALE hydrocode (Wünnemann et al., 2006), a multi-material, multi-rheology extension to the SALE hydrocode (Amsden et al., 1980), similar to the SALEB hydrocode (e.g.,Ivanov and Artemieva, 2002; Ivanov, 2005). iSALE includes a constitutive model for geologic materials, developed over several years, that accounts for changes in material shear strength that result from changes in pressure, temperature, and both shear and tensile damage (Melosh et al., 1992; Ivanov et al., 1997; Collins et al., 2004). For large impact crater formation this constitutive model is supplemented by a transient target weakening model, the acoustic fluidization "block-model”, which facilitates deep-seated gravitational collapse of the initial bowl-shaped transient cavity (Melosh and Ivanov, 1999). The thermodynamic behaviour of each material in the model is described by an equation of state (EoS). We used tables generated with the Analytic EoS (ANEOS, Thompson and Lauson, 1972) for dunite to represent the mantle, granite to represent the crust, and calcite to represent the sedimentary sequence. The code is well tested against laboratory experiments at low and high strain-rates (Wünnemann et al., 2006) and other hydrocodes (Pierazzo et al., 2008). Our choices of block-model and other input parameters were based on previous successful models of the Chicxulub impact (Ivanov, 2005; Collins et al., 2008), and are documented in Table 1. Fig. 6 shows cross-sections through three different vertical impact models at two stages during crater development. The left panels depict the time of maximum transient cavity depth, when the Moho is temporarily depressed downward to the maximum extent; the right panels depict the final crater, when the Moho is uplifted to the maximum extent. The three impact 
180 models differ only in impactor size, which included diameters of 10, 14, and $20 \mathrm{~km}$; in all

181 models the impactor was modeled as a granite sphere with a velocity of $12 \mathrm{~km} \mathrm{~s}^{-1}$. The target

182 comprised 3-km of sediment, 30-km of crust and a mantle half-space below. In Fig. 6a the

183 transient cavity reaches a maximum depth of $23 \mathrm{~km}$ and the width of the mantle depression is

$184<30 \mathrm{~km}$ radius; in Fig. $6 \mathrm{~b}$ the cavity reaches a maximum depth of $30 \mathrm{~km}$ and the width of the

185 mantle depression is <50 km radius; in Fig. 6c the cavity reaches a maximum depth of $40 \mathrm{~km}$ and

186 the width of the mantle depression is $>60 \mathrm{~km}$ radius. These models show a correlation between

187 maximum transient cavity depth and radius of mantle depression, with larger transient cavities

188 resulting in a greater radius of observed mantle depression. The models also show that mantle

189 deformation may be present even when the maximum transient cavity depth does not extend to

190 the base of the crust (Figs. 6a-6b).

\section{4. DISCUSSION AND CONCLUSIONS}

192 Our study consists of three components: a tomographic inversion for a crustal velocity

193 model, an inversion for 3-D Moho interface depth beneath the Chicxulub structure, and

194 numerical models to examine the Moho displacement predicted by vertical impact models for a

195 range of impactor sizes. The velocity model is similar to previous analyses (Morgan et al., 2000;

196 Morgan et al., 2002) except that it covers a more extensive offshore region. Increased velocities

197 are observed near the crater center, and are interpreted as 18-20 km of stratigraphic uplift of

198 lower crustal material (Christeson et al., 2001; Morgan et al., 2002). This central uplift is offset

199 from the crater center by $10-20 \mathrm{~km}$ to the west in both the velocity model ( Fig. 3) and in the

200 observed gravity field (Hildebrand et al., 2003) ( Fig. 1). The velocity model also constrains a

201 high-velocity region in the northwest, and a low-velocity region in the northeast (Fig. 3) which

202 correspond to an observed gravity high and gravity low, respectively (Fig. 1). The northwest

203 high-velocity and high-gravity region has previously been interpreted as shallow basement that

204 was likely a preexisting feature of the Cretaceous basement structure (Christeson et al., 2001). 
205 The northeast low-velocity and low-gravity region is associated with an anomalously deep basin

206 that is interpreted to predate the Chicxulub impact (Gulick et al., 2008).

207 The prominent feature in the Moho topography is an upwarping of 1.5-2.0 km near the crater 208 center, and a deepening of 0.5-1.0 km at a radial distance of $\sim 30-55 \mathrm{~km}$ from the center of the

209 Moho upwarping (Fig. 4). In contrast to the central uplift, the Moho upwarping is not

210 significantly offset from the crater center. If the central uplift and Moho upwarping are related by

211 a common causal mechanism, this implies that uplift of the crater floor (and/or, perhaps,

212 subsequent collapse) occurred in a preferred direction to the WSW. Previous numerical models

213 (e.g., Ivanov and Artemieva, 2002) suggested that the permanent Moho deformation observed in

214 the seismic data is a consequence of temporary downward displacement of the mantle during the

215 formation of a deep transient cavity, followed by rebound and uplift of the mantle directly

216 beneath the transient cavity as it collapses to form the final crater. However, these models show

217 variability in both transient crater depth and the net effect of downward then upward

218 displacement of the Moho. Model parameterizations have included a single-material target

219 (Collins et al., 2002), a two-layer (crust over mantle) target (Ivanov and Artemieva, 2002), and

220 multiple-layer (sediment, crust, mantle) targets (Ivanov, 2005; Collins et al., 2008); the transient

221 crater depth in these models varies from 30-43 km. The Moho topography, or the material at

222 Moho depths for the single layer model, is modeled as: 1) upwarping of 2-km near the crater

223 center and a deepening of $\sim 2 \mathrm{~km}$ between $\sim 5$ and $40 \mathrm{~km}$ from the crater center (Collins et al.,

224 2002), 2) downwarped to form a concavity with a depth of approximately 2-km and a radius of

22550 km (Ivanov and Artemieva, 2002; Ivanov, 2005), or 3) no net displacement directly beneath

226 the crater center, upwarped by $\sim 1 \mathrm{~km}$ between 5 and $25 \mathrm{~km}$ radial distance, and downwarped by

$227 \sim 1 \mathrm{~km}$ between 25 and $45 \mathrm{~km}$ radial distance (Collins et al., 2008). No published model of the

228 Chicxulub impact is entirely consistent with the Moho topography imaged by the seismic data, 229 although the simple single-layer model of Collins et al. (2002) provides the best fit to the seismic 230 observations. 
231 To investigate the effect of numerical model assumptions on mantle deformation, and to

232 refine existing models to better match the Moho topography inferred from the seismic data we

233 performed a suite of numerical models similar to those presented by Ivanov (2005) and Collins et

234 al. (2008) using a range of impactor sizes. Our best-fit model (Fig. 6b), which is similar to that of

235 Collins et al. (2008), shows mantle upwarping of $\sim 2-\mathrm{km}$ between the crater center and a radius of

$236 \sim 25 \mathrm{~km}$, surrounded by a deepening of $\sim 1 \mathrm{~km}$ between $\sim 25$ and $45 \mathrm{~km}$ from the crater center.

237 This is in reasonable agreement with the observed mantle deformation at Chicxulub. However,

238 our numerical models also show that the amount of vertical uplift of material beneath the

239 transient crater during collapse is very sensitive to the assumed effective strength of the target,

240 and in particular the difference in effective strength between the crust and mantle. As a

241 consequence of this model sensitivity, the amount of uplift of the Moho beneath the Chicxulub

242 crater may not provide a firm constraint on the size of the transient cavity. This also offers a

243 potential explanation for the variability in net Moho displacement in published models of the

244 Chicxulub impact.

245 Our new numerical models show that mantle deformation may be present even when the 246 maximum transient cavity depth does not extend to the base of the crust (Figs 6a-6b). Moreover,

247 the models also show a robust correlation between maximum transient cavity depth and radius of

248 mantle depression, with larger transient cavities resulting in a greater radius of observed mantle

249 depression (Fig. 6). Our models are for an impactor striking at a velocity of $12 \mathrm{~km} \mathrm{~s}^{-1}$. Faster

250 velocities will result in larger transient cavities for a fixed impactor size, but the relationship

251 between maximum transient cavity depth and radius of mantle depression remains the same.

252 Hence the width and amplitude of maximum downwarping of the Moho depends primarily on

253 the maximum depth of the transient cavity, regardless of the exact impact conditions under

254 which the cavity forms (velocity or size of the impactor). The relationship between maximum

255 transient cavity depth and radius of mantle depression is also insensitive to the assumed strength

256 of the crust and mantle; hence, the observed mantle deformation at Chicxulub places a robust

257 constraint on the transient crater depth. The observed mantle downwarping at radial distances 
258 between 30 and $50 \mathrm{~km}$ in Fig. 4d implies a maximum cavity depth of at least $30 \mathrm{~km}$. This result,

259 combined with an inferred transient crater diameter of 90-105 km (Morgan et al., 1997), implies

260 a transient crater depth-to-diameter ratio of $\sim 1: 3$, which is close to the ratio of $\sim 1: 2.7$ observed in

261 small-scale laboratory experiments and simple craters (e.g, Melosh, 1989). This suggests that the

262 depth-to-diameter ratio is relatively constant for all craters including the large multi-ring

263 Chicxulub impact crater. The fact that the mantle is uplifted at all in the observed Chicxulub

264 Moho demonstrates that collapse of the transient crater must involve deep-seated deformation,

265 and that stratigraphic uplift of rocks beneath large craters must persist to great depths beneath the

266 crater floor. The effective strength of the target beneath the crater immediately after impact must

267 be low enough to allow substantial upward movement of the crater floor before the inwardly

268 collapsing sides of the crater reach the center of the crater, where they would suppress the uplift.

269 This observation may help to distinguish between different styles of crater collapse suggested by

270 numerical models that employ alternative algorithms for reducing the strength of the target

271 during an impact (e.g., Stewart and Senft, 2007).

272 The structural uplift observed in the upper crust at Chicxulub is offset from the center of the

273 Moho upwarping (Fig. 3); we speculate that uplift of both the Moho and crust are linked and that

274 the asymmetry was produced during the collapse of the transient crater. In other words, we

275 hypothesize that uplift of the crater floor was not exactly vertical, but rather involved a

276 horizontal velocity component in the WSW direction. Whether this asymmetric collapse was a

277 consequence of oblique impact, lateral asymmetry in crustal strength, or random instabilities

278 during crater modification remains an open question. Numerical models of oblique impact

279 suggest that central uplifts do rise with a downrange velocity component (e.g., Ivanov and

280 Artemieva, 2002; Shuvalov and Dypvik, 2004) as suggested by Schultz and d'Hondt (1996).

281 This is supported by geological field evidence for preferred transport direction in central uplifts

282 at eroded terrestrial craters (Scherler et al., 2006; Kenkmann and Poelchau, 2009). Recent

283 numerical models of complex crater formation caused by oblique impact also suggest that, at

284 depth, the central uplift is situated beneath the center of the crater, while at the surface the central 
285

286

287

288

289

290

291

292

293

294

295

296

297

298

299

300

301

302

303

304

305

306

307

308

309

310

311

uplift is offset downrange of the crater center (Elbeshausen and Wünnemann, 2008; Wünnemann et al., 2009). Hence, if asymmetric central uplift collapse of the Chicxulub crater is related to the angle and direction of impact, the expected impact direction would be from the ENE. In contrast, remote sensing studies of central peak craters on Venus and the moon show no statistically significant relationship between impact direction and offset of the central uplift from the crater center (Eldholm et al., 1989; Herrick and Forsberg-Taylor, 2003; McDonald et al., 2008). This implies that the asymmetry in crustal and Moho uplifts observed at the Chicxulub crater may not be related to impact direction, but instead may be a consequence of lateral asymmetry in crustal strength, or random instabilities during crater collapse.

Studies of lunar craters reveal Moho topography similar in many ways to that observed at the Chicxulub crater. Modeling of lunar gravity data is non-unique with trade-offs between density contrasts and layer thicknesses, and is further complicated by the fact that crustal thickness is only constrained beneath the Apollo 12 and 14 sites (Toksöz et al., 1974). However, analyses do indicate that physically realistic gravity models require thinned crust beneath most large lunar craters (Neumann et al., 1996; Wieczorek and Phillips, 1998). Direct comparison of mantle deformation beneath lunar and terrestrial craters is complicated by the factor of $\sim 2$ difference in crustal thickness and by the factor of $\sim 6$ difference in surface gravity. The latter difference implies that impacts of the same mass and velocity will result in a transient crater approximately 6 times larger on the Moon than that formed on Earth (e.g., Holsapple, 1993). Hence, if the Chicxulub transient crater depth was $\sim 30 \mathrm{~km}$, the depth of a transient crater of equivalent scale on the Moon would be $\sim 180 \mathrm{~km}$. Assuming that collapse of the transient crater widens the diameter by the same factor on Earth as it does on the Moon, craters on the Moon may be considered to be crudely equivalent in scale to craters 6 times smaller on Earth (although the final crater depths will be different; see McKinnon et al. (1997)). In other words, Chicxulub may be compared (with caution) to lunar impact basins several hundreds of kilometers across. However, for Chicxulub the pre-impact depth of the crust-mantle boundary ( 35 km) was approximately the same as the transient crater depth, whereas the simple scaling arguments 
312 above suggest that for an equivalent-scale lunar crater the depth of the crust-mantle boundary

313 ( 60-80 km) would be substantially shallower than the transient crater depth $(\sim 180 \mathrm{~km})$. In this

314 case, mantle-uplift beneath the lunar crater would be much greater than that observed at

315 Chicxulub. Hence, substantial thinning of lunar crust beneath large impact basins on the Moon is

316 consistent with the amount of inferred mantle and lower-crustal uplift at Chicxulub based on

317 seismic data.

318 Crustal thickness models based on lunar gravity data also include an adjacent ring of

319 thickened crust around many craters that lies mainly within the basin rim, but this feature is not

320 as well-constrained and has been suggested to be an artefact of incorrect densities if the region

321 surrounding the basins is extensively brecciated or includes low-density ejecta deposits

322 (Neumann et al., 1996; Wieczorek and Phillips, 1998). However, an upwarped Moho beneath the

323 crater center surrounded by Moho downwarping is a component of models for both the

324 Chicxulub and lunar craters, and this similarity in Moho topography strongly suggests that the

325 ring of thickened crust is a real feature of lunar craters. Moho upwarping has also been modelled

326 beneath some large Martian craters (Neumann et al., 2004; Mohit and Philipps, 2007). These

327 observations from Chicxulub, lunar, and Martian craters suggest that mantle deformation can

328 play a prominent role in large crater formation.

329 ACKNOWLEDGEMENTS

330 We are grateful to the captains, crew, and science parties (onshore and offshore) during data

331 acquisition in 1996 and 2005. The modeling work in this paper would not have been possible

332 without the years of model development behind iSALE, for which we are indebted to Kai

333 Wünnemann, Boris Ivanov and Jay Melosh. We thank Linda Elkins-Tanton, John Hole, and 3

334 anonymous reviewers for their comments which have improved this manuscript. Our work was

335 supported by the National Science Foundation (NSF grants OCE-9415716, OCE-9818868, and

336 OCE-0221101) and the Natural Environmental Research Council. GSC was funded by NERC

337 grant NE/E013589/1. This is UTIG contribution 2068. 
338

339

340

341

342

343

344

345

346

347

348

349

350

351

352

353

354

355

356

357

358

359

360

\section{REFERENCES CITED}

Amsden, A.A., Ruppel, H.M., and Hirt, C.W., 1980, SALE: Simplified ALE Computer Program for Fluid Flow at all Speeds, Los Alamos National Laboratory Report Los Alamos, NM, Los Alamos National Laboratory, p. 101.

Brittan, J., Morgan, J., Warner, M., and Marin, L., 1999, Near-surface seismic expression of the Chicxulub impact crater, in Dressler, B.O., and Sharpton, V.L., eds., Large Meteorite

Impacts and Planetary Evolution II, Volume Geol. Soc. Am. Spec. Pap. 339, p. 269-279.

Christeson, G.L., Nakamura, Y., Buffler, R.T., Morgan, J., and Warner, M., 2001, Deep crustal structure of the Chicxulub impact crater: Journal of Geophysical Research, v. 106, p. 2175121769.

Collins, G.S., Melosh, H.J., and Ivanov, B.A., 2004, Modeling damage and deformation in impact simulations: Meteoritics and Planetary Science, v. 39, p. 217-231.

Collins, G.S., Melosh, H.J., Morgan, J.V., and Warner, M.R., 2002, Hydrocode simulations of

Chicxulub crater collapse and peak-ring formation: Icarus, v. 157, p. 24-33.

Collins, G.S., Morgan, J.V., Barton, P.J., Christeson, G.L., Gulick, S.P.S., Urrutia-Fucugauchi,

J., Warner, M.R., and Wünnemann, K., 2008, Dynamic modeling suggests terrace zone asymmetry in the Chicxulub crater is caused by target heterogeneity: Earth and Planetary Science Letters, v. 270, 221-230, doi.

Dence, M.R., 1965, The extraterrestrial origin of impact craters: Annual New York Academy of Science, v. 123, p. 941-969.

Elbeshausen, D., and Wünnemann, K., 2008, Complex crater formation driven by oblique meteorite impacts, Large Meteorite Impacts and Planetary Evolution IV Conference, p. 3078. 
361 Eldholm, O., Thiede, J., and Taylor, E., 1989, Evolution of the Vøring volcanic margin, Proc.

362 ODP, Sci Results, v. 104, Volume 104: College Station, TX, Ocean Drilling Program, p.

$363 \quad$ 1033-1065.

364 Gilbert, G.K., 1893, The moon's face: A study of the origin of its features: Bull. Philos. Soc.

365 Wash., v. 12, p. 241-292.

366 Grieve, R., and Therriault, A., 2000, Vredefort, Sudbury, Chicxulub: Three of a kind?: Annual

367 Review of Earth and Planetary Science, v. 28, p. 305-338.

368 Gulick, S.P.S., Barton, P.J., Christeson, G.L., Morgan, J.V., McDonald, M., Mendoza-Cervantes, 369 K., Pearson, Z.F., Surendra, A., Urrutia-Fucugauchi, J., Vermeesch, P.M., and Warner, M.R., 3702008 , Importance of pre-impact crustal structure for the asymmetry of the Chicxulub impact 371 crater: Nature Geosciences, v. 1, p. 131-135.

372 Hartmann, W.K., 1972, Interplanet variations in scale of crater morphology—Earth, Mars, 373 Moon: Icarus, v. 17, p. 707-713.

374 Herrick, R.R., and Forsberg-Taylor, N.K., 2003, The shape and appearance of craters formed by 375 oblique impact on the Moon and Venus: Meteoritics and Planetary Science, v. 38, p. 1551$376 \quad 1578$.

377 Hildebrand, A.R., Millar, J.D., Pilkington, M., and Lawton, D.C., 2003, Three dimensional 378 gravity field modelling of the Chicxulub impact crater: Meteoritics \& Planetary Science, v. 37938 Suppl., p. 150.

380 Hildebrand, A.R., Penfield, G.T., Kring, D.A., Pilkington, M., Camargo, A., Z., Jacobsen, S.B., 381 and Boynton, W.V., 1991, Chicxulub Crater: A possible Cretaceous/Tertiary boundary 382 impact crater on the Yucatán Peninsula, Mexico: Geology, v. 19, p. 867-871. 
383 Holsapple, K.A., 1993, The scaling of impact processes in planetary sciences: Annual Review of $384 \quad$ Earth and Planetary Science, v. 21, p. 333-373.

385 Ivanov, B.A., 2005, Numerical modeling of the largest terrestrial metorite craters: Solar System 386 Research, v. 39, p. 381-409.

387 Ivanov, B.A., and Artemieva, N.A., 2002, Numerical modeling of the formation of large impact 388 craters, in Koeberl, C., and MacLeod, K.G., eds., Catastrophic Events and Mass Extinctions: 389 Impacts and Beyond: Boulder, Colorado, Geological Society of America Special Paper 356, 390 p. 619-630.

391 Ivanov, B.A., Deniem, D., and Neukum, G., 1997, Implementation of dynamic strength models 392 into 2D hydrocodes: Applications for atmospheric breakup and impact cratering.: Int. J. 393 Impact Engineering, v. 20, p. 411-430.

394 Kenkmann, T., and Poelchau, M.H., 2009, Acute-angled collision with Earth: Geology, p. in 395 press.

396 Ludwig, W.J., Nafe, J.E., and Drake, C.L., 1970, Seismic refraction, in Maxwell, A.E., ed., The 397 Sea, Vol. 4, Part 1: New York, Wiley-Interscience, p. 53-84.

398 McDonald, M.A., Melosh, H.J., and Gulick, S.P.S., 2008, Oblique impacts and peak ring 399 position: Venus and Chicxulub: Geophysical Research Letters, v. 35, L07203, doi: $400 \quad 10.1029 / 2008 G L 033346$.

401 McKinnon, W.B., Zahnle, K.J., Ivanov, B.A., and Melosh, H.J., 1997, Cratering on Venus:

402 Models and observations, in Bougher, S.W., Hunten, D.M., and Phillips, R.J., eds., Venus II:

403 Tucson, Univ. Arizona Press, p. 969-1014.

404 Melosh, H.J., 1989, Impact Cratering: A Geological Process: New York, Oxford Univ. Press, $405 \quad 245 \mathrm{p}$. 
406

407

408

409

410

411

412

413

414

415

416

417

418

419

420

421

422

423

424

425

426

427

Melosh, H.J., and Ivanov, B.A., 1999, Impact crater collapse: Annual Review of Earth and Planetary Science, v. 27, p. 385-415.

Melosh, H.J., Ryan, E.V., and Asphaug, E., 1992, Dynamic Fragmentation in Impacts: Hydrocode Simulation of Laboratory Impacts: Journal of Geophysical Research, v. 97, p. 14735-14759.

Mohit, P.S., and Philipps, R.J., 2007, Viscous relaxation on early Mars: A study of ancient impact basins: Geophysical Research Letters, v. 34, L21204, doi: 10.1029/2007GL031252.

Morgan, J., and Warner, M., 1999, Chicxulub: The third dimension of a multi-ring impact basin: Geology, v. 27, p. 407-410.

Morgan, J., Warner, M., and Chicxulub Working Group, 1997, Size and morphology of the Chicxulub impact crater: Nature, v. 390, p. 472-476.

Morgan, J.V., Christeson, G.L., and Zelt, C.A., 2002, Testing the resolution of a 3D velocity tomogram across the Chicxulub crater: Tectonophysics, v. 355, p. 215-226.

Morgan, J.V., Warner, M.R., Collins, G.S., Melosh, H.J., and Christeson, G.L., 2000, Peak-ring

formation in large impact craters: Geophysical constraints from Chicxulub: Earth and

Planetary Science Letters, v. 183, p. 347-354.

Neumann, G.A., Zuber, M.T., Smith, D.E., and Lemoine, F.G., 1996, The lunar crust: Global structure and signature of major basins: Journal of Geophysical Research, v. 101, p. 1684116863.

Neumann, G.A., Zuber, M.T., Wieczorek, M.A., McGovern, P.J., Lemoine, F.G., and Smith, D.E., 2004, Crustal structure of Mars from gravity and topography: Journal of Geophysical Research, v. 109, E08002, doi: 10.1029/2004JE002262. 
428 O'Keefe, J.D., and Ahrens, T.J., 1999, Complex craters: Relationship of stratigraphy and rings to 429 impact conditions: Journal of Geophysical Research, v. 104, p. 27091-27104.

430 Pierazzo, E., Artemieva, N., Asphaug, E., Baldwin, E.C., Cazamias, J., Coker, R., Collins, G.S., 431 Crawford, D., Elbeshausen, D., Holsapple, K.A., Housen, K.R., Korycansky, D.G., and 432 Wünnemann, K., 2008, Validation of numerical codes for impact and explosion cratering: 433 Meteoritics and Planetary Science, p. in press.

434 Reimold, W.U., and Gibson, R.L., 1996, Geology and evolution of the Vredefort imact structure, 435 South Africa: J. Afr. Earth Sci., v. 23, p. 125-162.

436 Scherler, D., Kenkmann, T., and Jahn, A., 2006, Structural record of an oblique impact: Earth 437 and Planetary Science Letters, v. 248, p. 43-53.

438 Schultz, P.H., 1976, Moon morphology : Interpretations based on Lunar Orbiter photography: 439 Austin, University of Texas Press.

440 Schultz, P.H., and D'Hondt, S., 1996, Cretaceous-Tertiary (Chicxulub) impact angle and its 441 consequences: Geology, v. 24, p. 963-967.

442 Sharpton, V.L., Dalyrymple, G.B., Marin, L.E., Ryder, G., Schuraytz, B.C., and Urrutia443 Fucugauchi, J., 1992, New links between the Chicxulub impact structure and the 444 Cretaceous/Tertiary boundary: Nature, v. 359, p. 819-821.

445 Shuvalov, V., and Dypvik, H., 2004, Ejecta formation and crater development of the Mjølnir 446 impact: Meteoritics and Planetary Science, v. 39, p. 467-479.

447 Stewart, S.T., and Senft, L.E., 2007, Frictional melting and complex crater collapse, Bridging the 448 Gap II: Effect of Target Properties on the Impact Cratering Process: Saint-Hubert, Canada, p. $449 \quad$ Abstract 8021. 
450 Swisher, C.C., III, Grajales-Nishimura, J.M., Montanari, A., Margolis, S.V., Claeys, P., Alvarez, 451 W., Renne, P., Cedillo-Pardo, E., Maurrasse, F.J.-M.R., Curtis, G.H., Smit, J., and 452 McWilliams, M.O., 1992, Coeval ${ }^{40} \mathrm{Ar} /{ }^{39} \mathrm{Ar}$ ages of 65.0 million years ago from Chicxulub 453 crater melt rock and Cretaceous-Tertiary boundary tektites: Science, v. 257, p. 954-958.

454 Talwani, M., Worzel, J.L., and Landisman, M., 1959, Rapid gravity computations for two455 dimensional bodies with application to the Mendocino submarine fracture zone [Pacific Ocean]: Journal of Geophysical Research, v. 64, p. 49-59.

457 Thompson, S.L., and Lauson, H.S., 1972, Improvements in the Chart D radiation-hydrodynamic 458 CODE III: Revised analytic equation of state: Albuquerque, N. Mex., USA, Sandia 459 Laboratories, Report SC-RR--71-0714, p. 119.

460 Toksöz, M.N., Dainty, A.M., Solomon, S.C., and Anderson, K.R., 1974, Structure of the Moon: 461 Reviews of Geophysics, v. 12, p. 539-567.

462 Vermeesch, P.M., and Morgan, J.V., 2008, Structural uplift beneath the Chicxulub impact 463 structure: Journal of Geophysical Research, v. 113, B07103, doi: 10.1029/2007JB005393. 464 Vermeesch, P.M., Morgan, J.V., Christeson, G.L., Barton, P.J., and Surendra, A., 2009, Three465 dimensional joint inversion of traveltime and gravity data across the Chicxulub impact crater: 466 Journal of Geophysical Research, v. 114, B02105, doi: 10.1029/2008JB005776.

467 Wieczorek, M.A., and Phillips, R.J., 1998, Potential anomalies on a sphere: Applications to the 468 thickness of the lunar crust: Journal of Geophysical Research, v. 103, p. 1715-1724.

469 Wilhelms, D.E., McCauley, J.F., and Trask, N.J., 1987, The Geologic History of the Moon:

470 Reston, VA, U.S. Geological Survey Professional Paper 1348.

471 Wise, D.U., and Yates, M.T., 1970, Mascons as structural relief on a lunar 'Moho': Journal of $472 \quad$ Geophysical Research, v. 75, p. 261-268. 
473 Wünnemann, K., Collins, G.S., and Melosh, H.J., 2006, A strain-based porosity model for use in 474 hydrocode simulations of impacts and implications for transient crater growth in porous 475 targets: Icarus, v. 180, p. 514-527.

476 Wünnemann, K., Elbeshausen, D., and Collins, G.S., 2009, Structural evidence for the direction 477 of impact at complex craters: Insight from 3D numerical modeling, 40th Lunar and Planetary $478 \quad$ Science Conference, p. in press.

479 Zelt, C.A., and Barton, P.J., 1998, Three-dimensional seismic refraction tomography: A 480 comparison of two methods applied to data from the Faeroe Basin: Journal of Geophysical $481 \quad$ Research, v. 103, p. 7187-7210.

482 Zelt, C.A., Sain, K., Naumenko, J.V., and Sawyer, D.S., 2003, Assessment of crustal velocity 483 models using seismic refraction and reflection tomography: Geophysical Journal 484 International, v. 153, p. 609-626. 
Table 1 Numerical Model Parameters

\begin{tabular}{|c|c|c|c|c|}
\hline Symbol & Definition & \multicolumn{3}{|l|}{ Value } \\
\hline$L$ & Impactor diameter $(\mathrm{km})$ & \multicolumn{3}{|c|}{$10,14,20$} \\
\hline$v_{i}$ & Impact velocity $(\mathrm{km} / \mathrm{s})$ & \multicolumn{3}{|l|}{12} \\
\hline$\rho_{i}$ & Impactor density $\left(\mathrm{kg} / \mathrm{m}^{3}\right)$ & \multicolumn{3}{|l|}{2680} \\
\hline$T_{d e c}$ & Decay time of acoustic vibrations (s) & \multicolumn{3}{|c|}{$100,140,200^{\S}$} \\
\hline \multirow{3}{*}{$v_{\lim }$} & Kinematic viscosity of & \multicolumn{3}{|c|}{$2,2.8,4^{\S}$} \\
\hline & \multicolumn{4}{|l|}{ acoustically fluidized region $\left(\times 10^{5} \mathrm{~m}^{2} / \mathrm{s}\right)$} \\
\hline & & Mantle & Crust & Sediments \\
\hline$\rho$ & Reference density $\left(\mathrm{kg} / \mathrm{m}^{3}\right)$ & 3310 & 2680 & 2700 \\
\hline$Y_{0}$ & Cohesion (Yield strength at zero pressure; MPa) & 50 & 50 & 5 \\
\hline$Y_{m}$ & $\begin{array}{l}\text { von Mises plastic limit (theoretical } \\
\text { yield strength at infinite pressure; GPa) }\end{array}$ & 3.5 & 2.5 & 0.5 \\
\hline$\mu_{i}$ & Coefficient of internal friction & 1.5 & 1.5 & 1.0 \\
\hline$\mu_{d}$ & Coefficient of friction (damaged material) & 0.6 & 0.6 & 0.4 \\
\hline$T_{m}$ & Melt temperature $\left({ }^{\circ} \mathrm{K}\right)$ & 1436 & 1673 & 1500 \\
\hline$\xi$ & Thermal softening parameter & 0.7 & 1.2 & 1.2 \\
\hline$p_{b d}$ & Brittle-ductile transition pressure (GPa) & 3.59 & 2.59 & 0.76 \\
\hline$p_{b p}$ & Brittle-plastic transition pressure (GPa) & 4.75 & 3.41 & 0.92 \\
\hline
\end{tabular}

$487{ }^{\S}$ The decay time of the acoustic vibrations and kinematic viscosity of the fluidized region were assumed 488 to scale proportionally with impactor diameter based on the results of Wünnemann and Ivanov (2003) 
489 Fig. 1. Experiment location; background image is bouguer gravity anomaly map (gravity data 490 courtesy of A. Hildebrand and M. Pilkington). Heavy black line marks the coastline. Black-white 491 dashed and white solid lines indicate the locations of the 1996 and 2005 multichannel seismic 492 profiles, respectively. Circles mark the ocean bottom and land seismometer locations used in our 493 analysis from the 1996 (yellow) and 2005 (maroon) experiments; record sections of marked 494 instruments are displayed in Fig. 2. Inset depicts the regional setting, with red rectangle outlining 495 the region shown in the main location figure.

496 Fig. 2. Representative record sections; instrument locations are shown in Fig. 1. a) Shots 497 recorded by OBS 01 from Chicx-A/A1 during 1996 experiment; b) Shots recorded by land 498 seismometer D46 from Chicx-A/A1 during 1996 experiment; c) Shots recorded by land 499 seismometer 047 from Chicx-R3 during 2005 experiment. All data have been bandpass filtered 500 with a low cut of $5 \mathrm{~Hz}$ and a high cut of $15 \mathrm{~Hz}$. Record sections are plotted with a reduction 501 velocity of $6 \mathrm{~km} / \mathrm{s}$, and have a 1.0 second automatic gain control applied. $P g$ and $P m P$ arrivals 502 are marked.

503 Fig. 3. Velocity model slices plotted as anomaly with respect to average velocity at each depth; 504 only regions constrained by ray coverage are shown. a) Slice at $5 \mathrm{~km}$ depth; contour interval is 5050.1 km/s. Yellow lines mark location of slices plotted in Figs. 3b, 3c, and 3d; heavy dark solid 506 line marks coastline. b) Slice along Chicx-BF profile; c) Slice along Chicx-CE profile; d) Slice 507 approximately parallel with the coastline. Crater center is marked by the star in Fig. 3a, and by 508 distance $=0$ in Figs. 3b, 3c, and 3d.

509 Fig. 4. a) Moho interface with inversion parameterized to solve for flattest interface. Interface is 510 only displayed at reflection points. b) As for Fig. 4a, except inversion parameterized to solve for 511 smoothest interface. c) Dipping interface that represents regional Moho trend. e) Depth anomaly 512 between flattest Moho interface and dipping regional trend. 
513 Fig. 5. Left) Difference between observed and calculated $P m P$ travel times for the model

514 displayed in the right panel; data is decimated by a factor of 25 for plotting purposes. Radial

515 distance is measured from the approximate center of the modeled Moho upwarping near the

516 crater center. Red line is a polynomial fit to the errors. Right) a) Regional Moho model (Fig. 4c);

517 profile location is approximately parallel to coastline. b) Moho inversion model (Fig. 4a); profile

518 location is approximately parallel to coastline. c) 5-km-thick velocity anomaly model that can

519 approximate observed $P m P$ travel times at most radial distances. d) 10-km-thick velocity

520 anomaly model that can approximate observed PmP travel times at most radial distances. e) 15-

521 km-thick velocity anomaly that can approximate observed $P m P$ travel times at most radial

522 distances.

523 Fig. 6. Numerical modeling results. a) 10-km diameter impactor; b) 14-km diameter impactor; c)

524 20-km diameter impactor. Light gray is sediments, medium gray is crystalline basement, and

525 dark gray is mantle. Left panels display transient cavities at the time of maximum crater depth

526 and the right panels depict the final crater. 

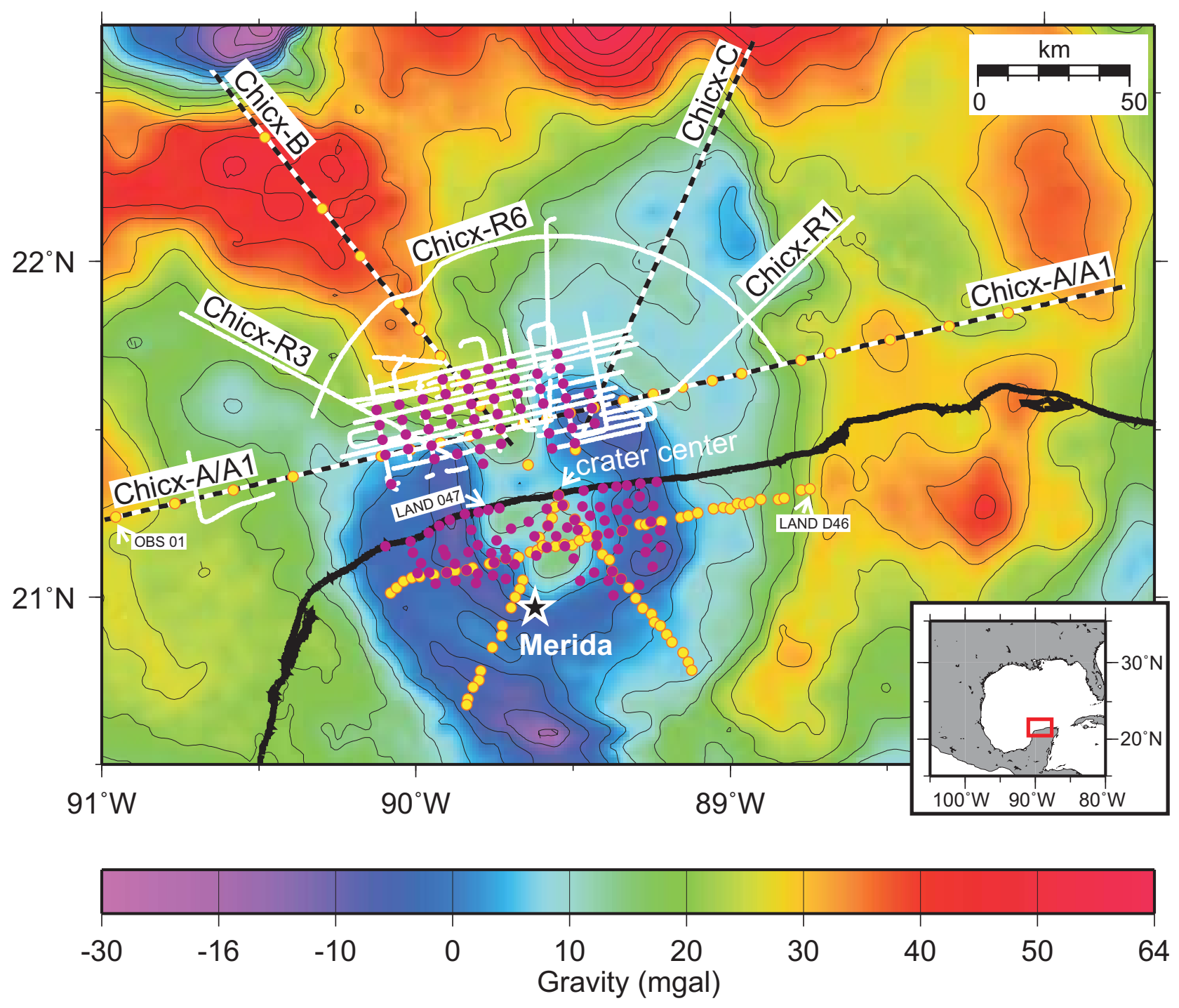

Figure 1 

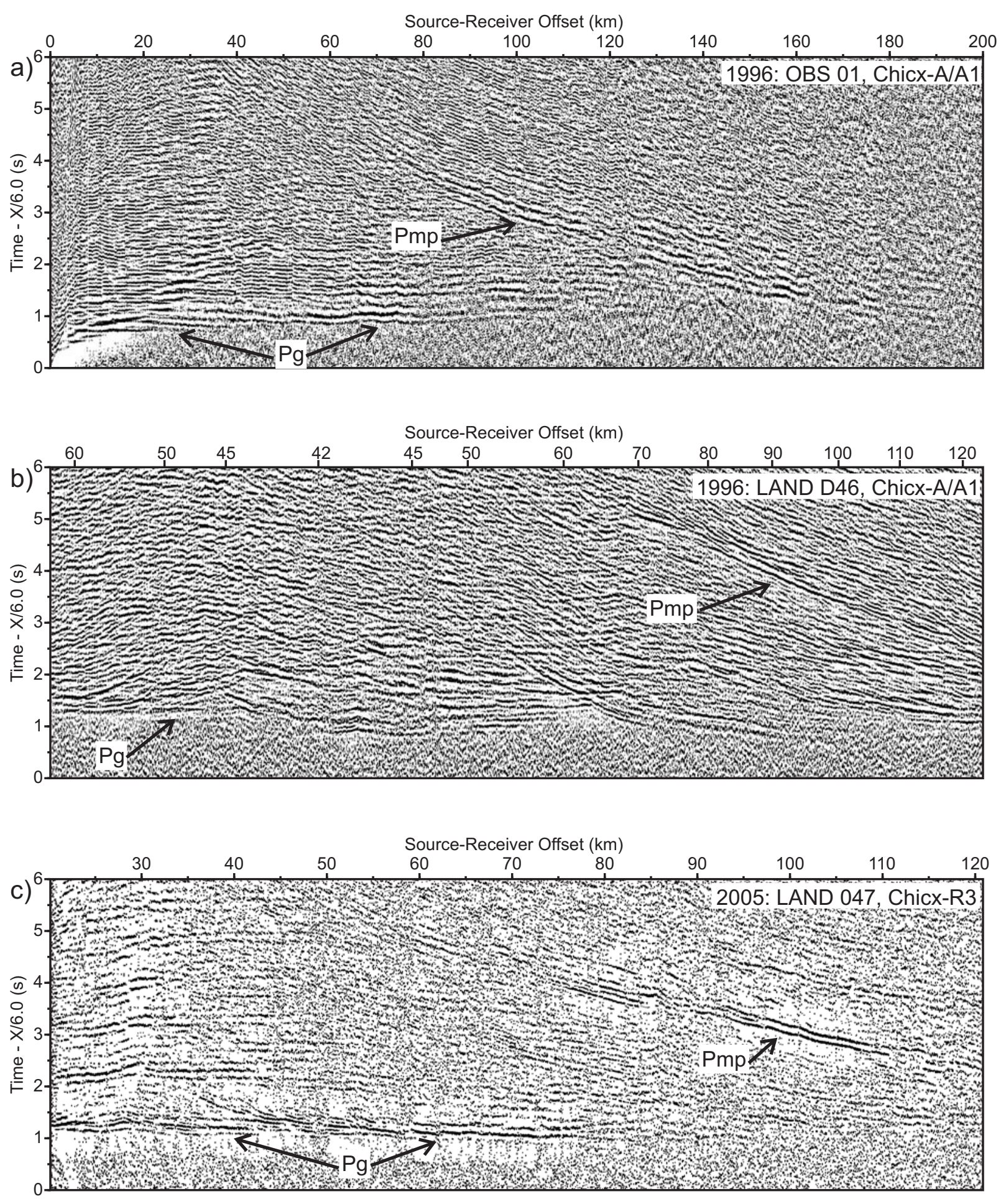

Figure 2 

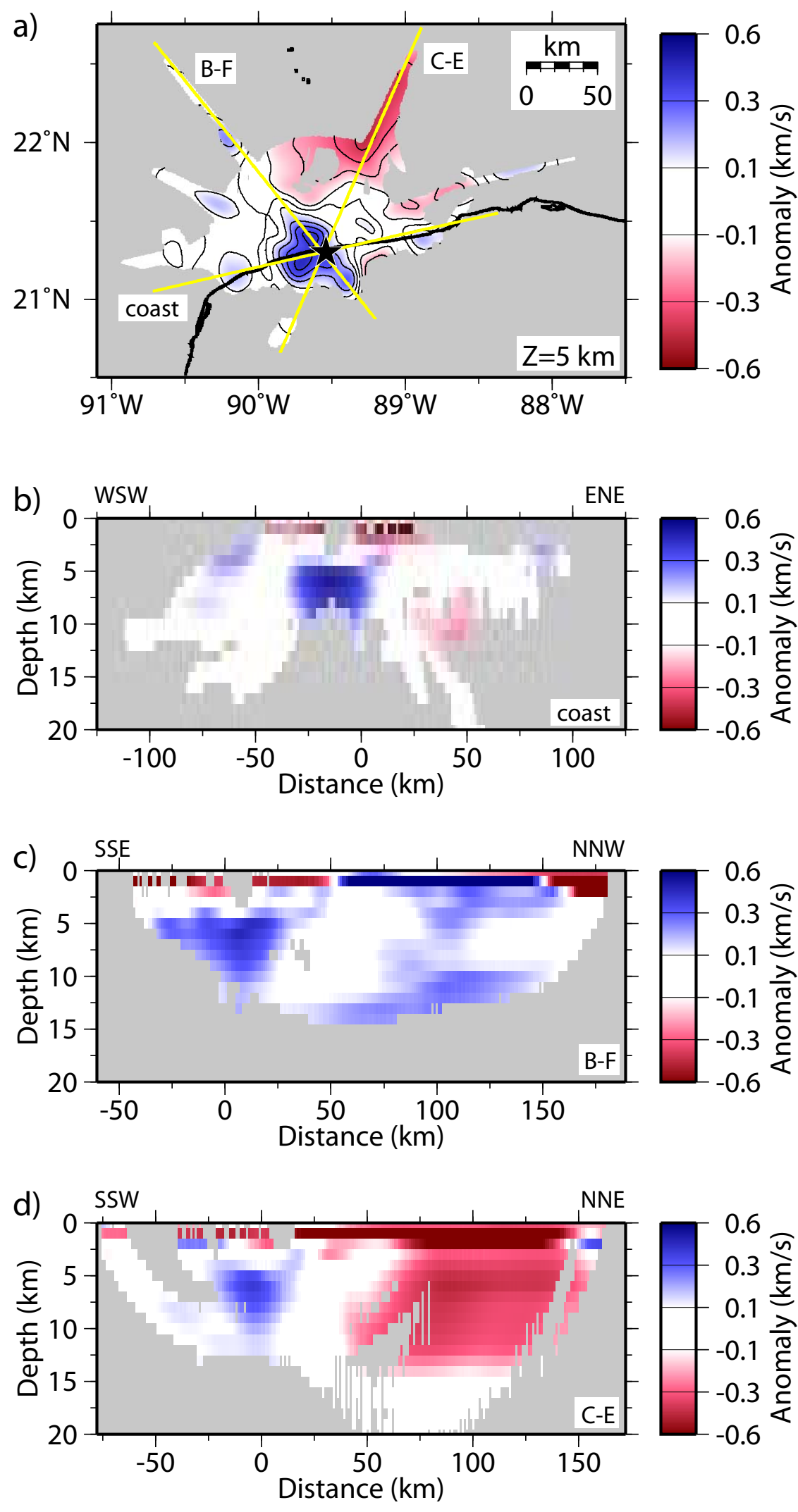

Figure 3 

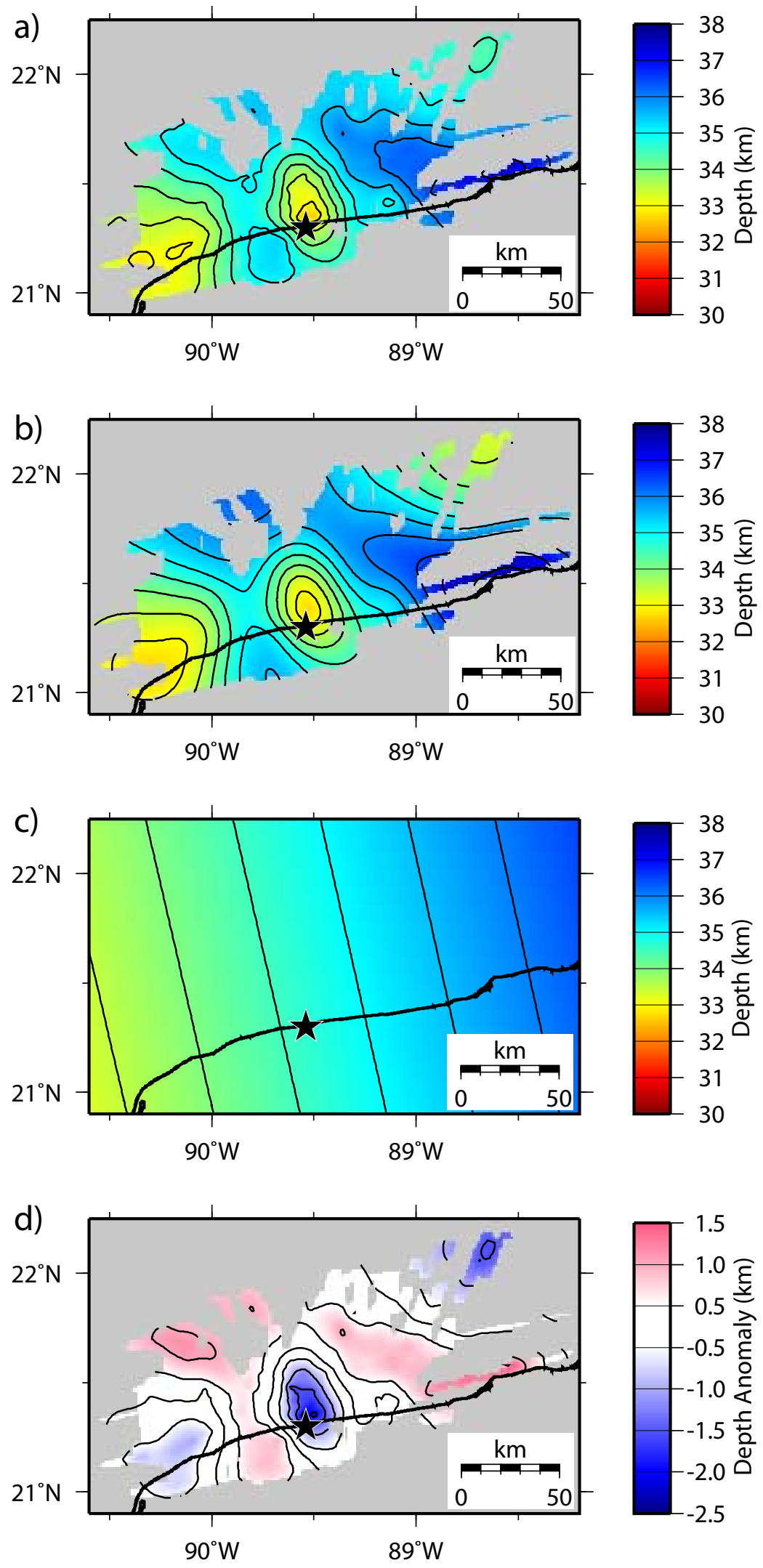

Figure 4 

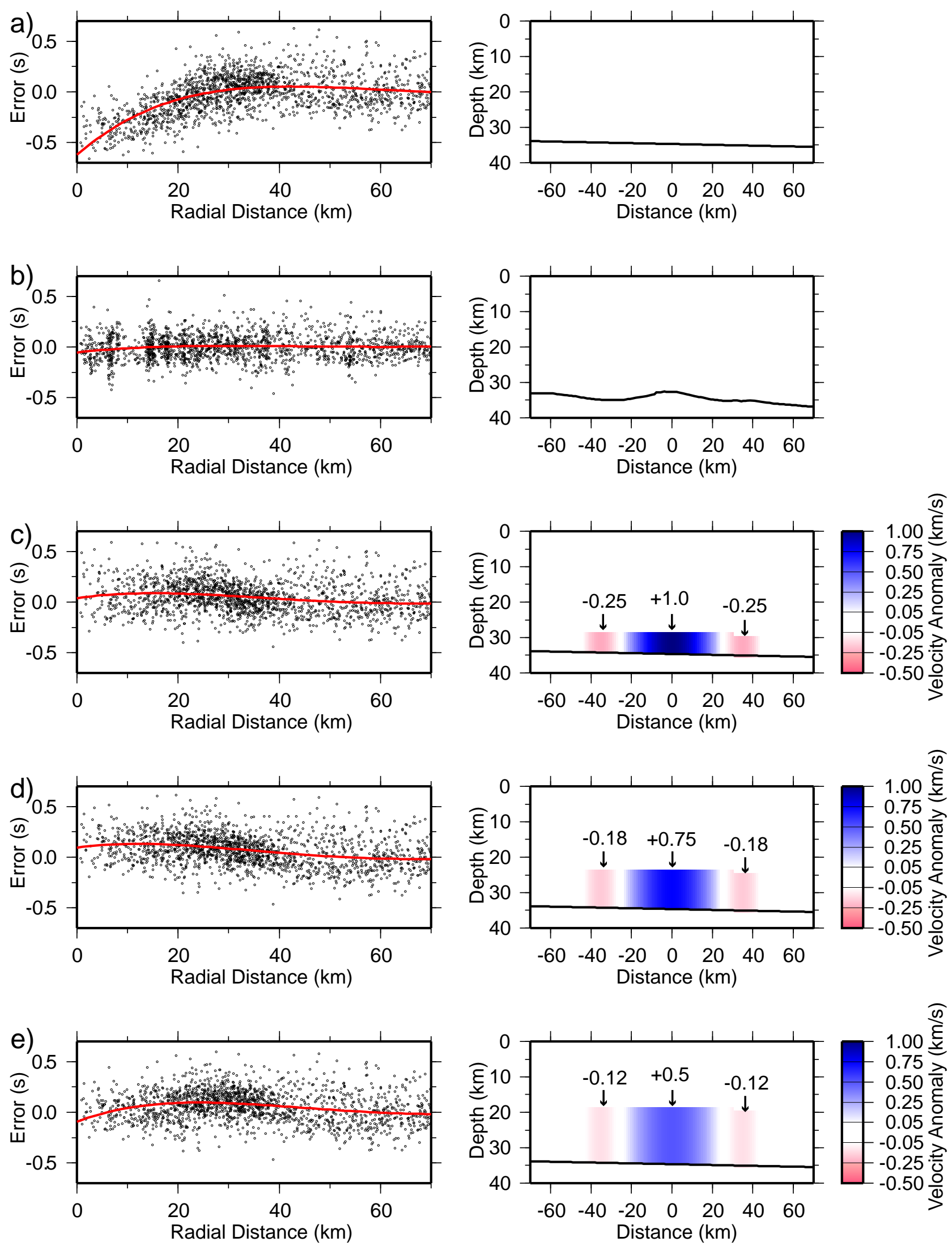

Figure 5 

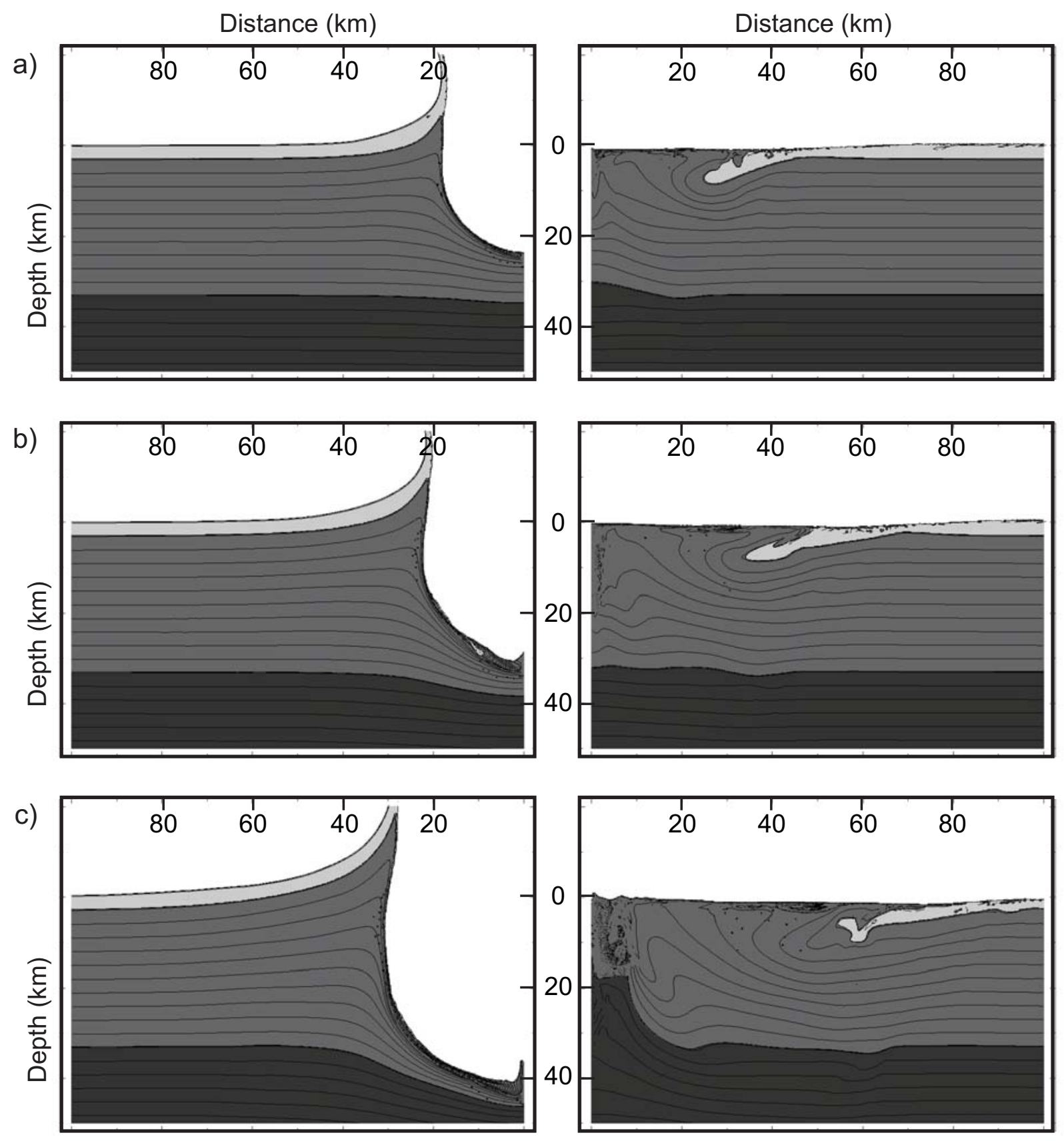

Figure 6 